\title{
Avaliação da atenção psicossocial em álcool e outras drogas na perspectiva dos
}

\section{pacientes}

\author{
Assessment of psychosocial care in alcohol and other drugs from the perspective of patients \\ Evaluación de la atención psicosocial em alcohol y otras drogas desde la perspectiva de los
}

pacientes

Recebido: 25/06/2021 | Revisado: 04/07/2021 | Aceito: 05/07/2021 | Publicado: 16/07/2021

\author{
Ricardo Henrique Soares \\ ORCID: https://orcid.org/0000-0003-4412-1974 \\ Tribunal de Justiça de São Paulo, Brasil \\ E-mail: rhssoares@gmail.com \\ Márcia Aparecida Ferreira de Oliveira \\ ORCID: https://orcid.org/0000-0002-1069-8700 \\ Universidade de São Paulo, Brasil \\ E-mail: marciaap@usp.br
}

\begin{abstract}
Resumo
Os processos de avaliação de serviços de saúde têm se valido dos relatos dos próprios usuários como mais um elemento na composição de parâmetros de avaliação de resultados. Este estudo objetivou avaliar a satisfação dos pacientes e sua percepção de mudanças decorrentes da assistência prestada por um serviço de atenção psicossocial em álcool e drogas. O estudo, descritivo, transversal e qualitativo, empregou referencial teórico-metodológico da Avaliação de Quarta Geração adaptado, coletando-se os dados por meio de observação, entrevistas individuais com a realização do Círculo Hermenêutico-dialético e entrevistas grupais. Os usuários manifestaram-se no sentido de que se sentem satisfeitos com o atendimento oferecido pelo serviço, enfatizando a qualidade do acolhimento. Com relação à percepção de mudanças, os participantes reconheceram mudanças positivas em suas vidas como resultados do tratamento, destacando mudanças relativas ao uso de substâncias psicoativas, à organização de suas vidas e em relação aos seus laços familiares.

Palavras-chave: Pesquisas sobre serviços de saúde; Transtornos relacionados ao uso de substâncias; Serviços comunitários de saúde mental; Satisfação pessoal.
\end{abstract}

\begin{abstract}
The processes of assessment of health services have used the reports of the users as element in the composition of parameters of evaluation of results. This study aimed to evaluate patients' satisfaction and their perception of changes resulting from the care provided by a psychosocial care service in alcohol and drugs. The descriptive, cross-sectional and qualitative study employed the theoretical-methodological reference of the Adapted Fourth Generation Assessment, collecting data through observation, individual interviews with the Hermeneutic-Dialectic Circle and group interviews. The users expressed that they feel satisfied with the service offered by the service, emphasizing the quality of the reception. Regarding to the perception of change, the participants recognized positive changes in their lives as treatment outcomes, highlighting effects on the use of psychoactive substances, the organization of their lives and their family ties.

Keywords: Health services research; Substance-related disorders; Community mental health services; Personal satisfaction.

\section{Resumen}

Los procesos de evaluación de servicios de salud se han valido de los relatos de los usuarios en la composición de parámetros de evaluación de resultados. Este estudio objetivó evaluar la satisfacción de los pacientes y su percepción de cambios derivados de la asistencia prestada por un servicio de atención psicosocial en alcohol y drogas. El estudio, descriptivo, transversal y cualitativo, empleó referencial teórico-metodológico de la Evaluación de Cuarta Generación adaptado, recogiendo los datos por medio de observación, entrevistas individuales con la realización del Círculo Hermenéutico-dialéctico y entrevistas grupales. Los usuarios sienten satisfechos con la atención ofrecida por el servicio, enfatizando la calidad de la acogida. Con respecto a la percepción de cambios, los participantes reconocieron cambios positivos en sus vidas como resultados del tratamiento, destacando cambios relativos al uso de sustancias psicoactivas, a la organización de sus vidas y en relación a sus lazos familiares.

Palavras clave: Investigación em servicios de salud; Trastornos relacionados com substancias; Servicios comunitários de salud mental; Satisfacción personal.
\end{abstract}




\section{Introdução}

Os processos de avaliação de serviços de saúde têm se valido dos relatos dos próprios pacientes como mais um elemento na composição de parâmetros de avaliação de resultados do tratamento oferecido pelos serviços de saúde (Bandeira, Andrade, Costa, \& Silva, 2011).

A percepção dos pacientes como fator de avaliação dos serviços de saúde tem sido incluída nos processos avaliativos em função da relevância dessas informações, que geralmente não estão disponíveis entre os dados clínicos coletados pelos profissionais, como no caso de mudanças sintomáticas, de funcionamento do paciente e de mudanças relativas a seu bem-estar. A inclusão dessas informações é considerada importante para os processos avaliativos dos serviços e para o próprio aperfeiçoamento do tratamento, uma vez que representam conhecimentos peculiares trazidos pelos pacientes (Bandeira, Andrade, Costa, \& Silva, 2011).

Ademais, Bandeira, Andrade, Costa e Silva (2011) ressaltam que a incorporação da percepção dos pacientes nos processos de avaliação do tratamento contribui para a percepção de empoderamento, a partir do momento em que os pacientes observam que suas informações são consideradas na aferição dos resultados do tratamento, favorecendo, ainda, na manutenção da adesão ao tratamento e no aumento dos níveis de satisfação com o serviço de saúde.

A percepção de mudanças tem sido associada a questão da satisfação dos pacientes com os serviços de saúde. Pesquisas apontam que mudanças observadas pelos profissionais do serviço, que não foram percebidas pelos pacientes como mudanças efetivamente positivas, não contribuem para o aumento dos níveis de satisfação dos pacientes com os serviços de saúde (Bandeira, Felicio, \& Cesari, 2010; Bandeira, Andrade, Costa, \& Silva, 2011).

As informações acerca da satisfação e da percepção dos pacientes a respeito dos resultados do tratamento oferecido pelos serviços de saúde têm sido compiladas em pesquisas de avaliação por meio de instrumentos de medida. Em pesquisas avaliativas de abordagem quantitativa realizadas nos Centros de Atenção Psicossocial em Álcool e outras Drogas (CAPSad) ficou demonstrado que os usuários estão satisfeitos com o serviço disponibilizado e que a maioria considerou estar melhor do que antes do tratamento, percebendo mudanças positivas em suas vidas (Barbosa, 2013; Pinho, 2014; Gonçalves, 2016; Gonçalves, Oliveira, Claro, Pinho, Prates et al., 2017).

Com o objetivo de avaliar a satisfação dos usuários e sua percepção de mudanças decorrentes do tratamento oferecido por um serviço de atenção psicossocial em álcool e outras drogas, o presente estudo constitui-se de um recorte de uma pesquisa de avaliação participativa, de natureza qualitativa, com vistas a produzir conhecimentos complementares aos apresentados pelas pesquisas de abordagem quantitativa.

\section{Metodologia}

Tratando-se de pesquisa envolvendo seres humanos, o presente estudo foi conduzido rigorosamente conforme os ditames éticos concernentes aos seres humanos (Brasil, 2012; Brasil, 2016).

$\mathrm{O}$ projeto de pesquisa obtive aprovação dos comitês de ética em pesquisa da instituição proponente (CAAE 64443717.7.0000.5392/ Parecer 1.969.819) e da instituição coparticipante (CAAE 64443717.7.3001.0086/ Parecer 1.990.622).

Trata-se de um estudo descritivo, transversal e de abordagem qualitativa. A coleta de dados se deu em um CAPSad do município de São Paulo (SP), com a participação de dez usuários atendidos no serviço.

As pesquisas de natureza qualitativa caracterizam-se pelo estudo de questões particulares e trabalham com a intensidade dos fenômenos, com os aspectos e significados que os tornam específicos e singulares (Minayo, 2017).

Este estudo empregou o referencial teórico-metodológico da Avaliação de Quarta Geração adaptado por Wetzel (2005), que faz uma aproximação entre o modelo de Avaliação de Quarta Geração (AQG) de Guba e Lincoln (2011) e do método Paidéia, 
de Campos (2005b). A possibilidade desse alinhamento de métodos proposto por Wetzel (2005) é baseada, de acordo com Furtado (2001) no referencial participativo e construtivista comum a ambos os modelos.

Wetzel (2005) estabelece, como técnicas para a coleta de dados, a observação, entrevistas individuais aplicando-se o método do Círculo Hermenêutico-dialético (CHD) e entrevistas grupais, compreendendo sete etapas para a realização do processo avaliativo:

1) contato com o campo de estudo: etapa na qual o projeto de pesquisa é submetido à gestão do serviço de saúde (objeto da avaliação);

2) organização da avaliação: momento da inserção do pesquisador no serviço visando a construção de relações de confiança com os interessados no processo avaliativo;

3) identificação dos grupos de interesses: etapa de reconhecimento e classificação de grupos compostos por pessoas que detém interesses comuns;

4) desenvolvimento de construções conjuntas: fase de realização das entrevistas individuais, aplicando-se o método do CHD (Figura 1) para cada grupo de interesse previamente identificado. A aplicação do CHD segue o método comparativo constante, o qual estabelece que o pesquisador realize uma análise da entrevista antecedente antes de proceder à entrevista subsequente, identificando dados importantes acerca da avaliação. Na posse desses dados, chamados de unidades de informação, o pesquisador deve apresentá-los ao próximo respondente, convidando-o a tecer comentários a seu respeito. De modo que esse processo segue até o último respondente, possibilitando que as unidades de informação sejam avaliadas por todos os participantes do círculo, que no caso do presente estudo foi composto por dez usuários do serviço, que aceitaram livremente participar da pesquisa, cuja coleta de dados ocorreu entre abril e junho de 2017.

5) esclarecimento das construções conjuntas: oportunidade que o pesquisador tem para introduzir informações que possam ampliar o conhecimento dos interessados acerca das construções conjuntas. Essas informações podem ser trazidas tanto da literatura quanto da própria observação do avaliador.

6) preparação para apresentação das questões para os grupos de interesse: essa etapa envolveu a logística para a realização da entrevista em grupo. Os dez usuários do serviço que participaram do círculo de entrevistas individuais (etapa 4) foram convidados para uma entrevista em grupo. Foi impresso material contendo as unidades de informação para ser distribuído aos participantes no momento da entrevista em grupo, a fim de acompanharem a leitura dos resultados provisórios da avaliação e discutir os itens apresentados;

7) realização da entrevista em grupo: nesta etapa foi realizada a entrevista em grupo, que contou com a presença de sete dos dez usuários convidados (etapa 6), na qual foi apresentada a devolutiva dos resultados provisórios com vistas à obtenção da validação das construções conjuntas (consensuais, compartilhadas), bem como foi realizada a negociação das construções conflitantes, objetivando o consenso. 
Figura 1. Círculo Hermenêutico-dialético.

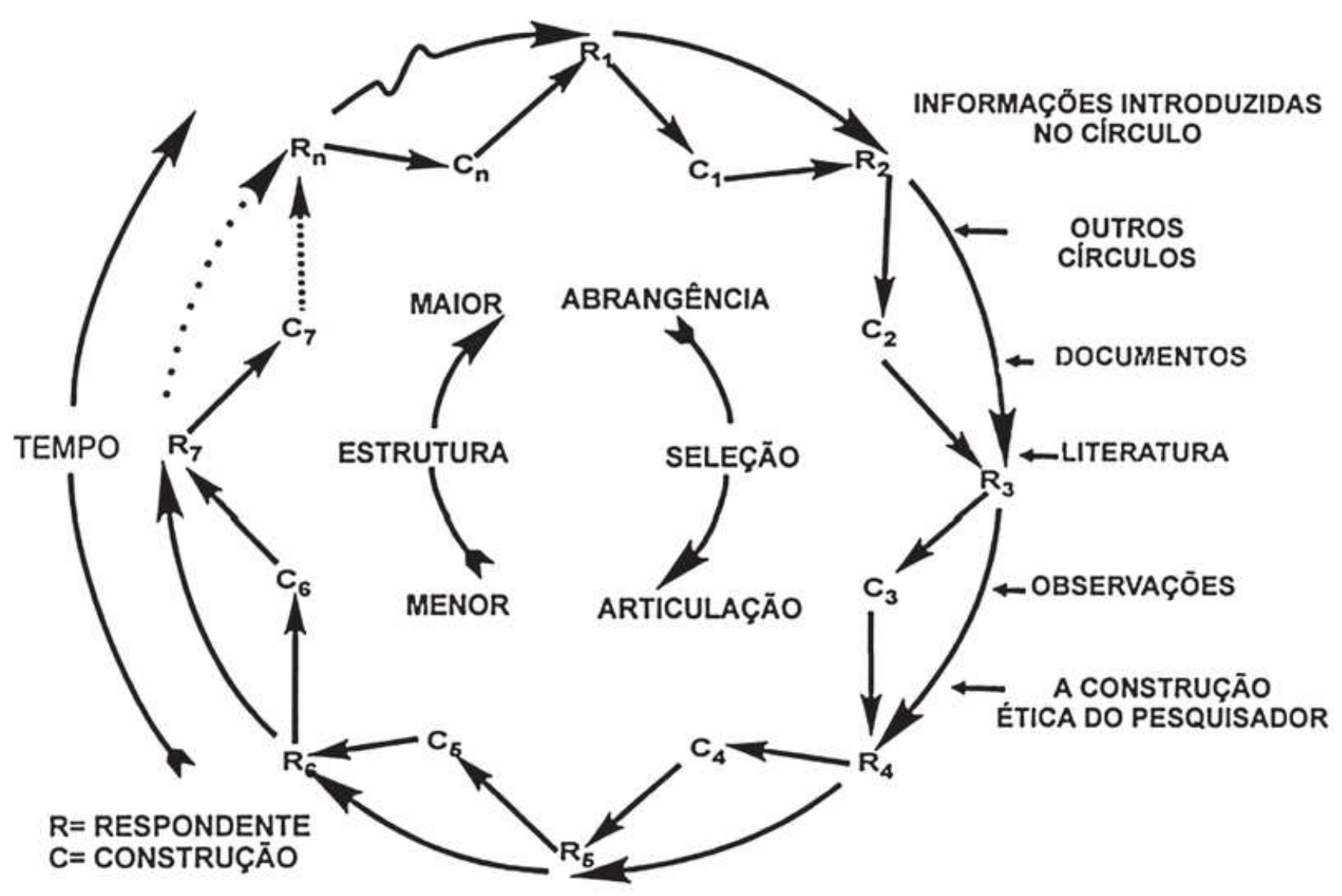

Fonte: Guba e Lincoln (2011, p. 169)

\section{Resultados}

Em função de apresentar identidade de sentidos, as construções compartilhadas que emergiram do grupo de usuários do CAPSad acerca da satisfação e da mudança percebida foram agrupadas em um mesmo núcleo temático, denominado neste estudo como "cuidado".

\subsection{Avaliação da satisfação dos usuários}

O tema "cuidado", no sentido do atendimento oferecido pelo CAPSad aos usuários, apresentou-se como central, tanto nas manifestações do grupo de usuários a respeito da satisfação, quanto acerca da mudança percebida. Consoante os relatos a seguir, o grupo de usuários expressou de maneira consensual sua satisfação com o serviço do CAPSad:

Tô muito satisfeito às vezes eu que não satisfaço eles porque tem dia que dá vontade de tomar uma e pra quem é especialista só de olhar no seu rosto já sabe que você tomou uma mas eu tô fazendo o possível eu tô quase parando devido o tratamento que eles fazem aqui com a gente tem que valorizar [...] o tratamento que eles me dão aqui pra mim já é suficiente pra mim deixar o vício porque eu sou muito bem tratado aqui. (E1U)

O Caps tá me ajudando em muitas coisas porque tipo eu cheguei aqui muito depressivo não vou te falar que estou $100 \%$ não eles dão todas as ferramentas e o caminho pra gente seguir e o apoio vai da nossa determinação também seguir isso daí. (E2U) 
Tô satisfeito com o tratamento com as pessoas que trabalham aqui. (E6U)

Eu estou presentemente muito satisfeito embora nós devamos considerar a seguinte questão eu estive aqui no ano de 2015 dei início a um tratamento e não dei continuidade a esse tratamento mas o primeiro contato com esta unidade ali em 2015 foi um contato bastante positivo eu sempre tive um muito bom atendimento por parte dos profissionais naquela ocasião [...] atualmente 2017 eu retorno a esta unidade especificamente pelo fato de ter me sentido bem de ter sido bem atendido de ter tido uma boa impressão dos profissionais que fazem atendimento aqui [...] eu estou reforçando as primeiras impressões que são boas. (E7U)

Minha satisfação por enquanto eu não tenho o que reclamar não porque eu conheço o Caps desde 2002 e toda vez que eu fiz recuperação no Caps eu fiquei 10 anos sem usar drogas depois eu me afastei do Caps eu não vim mais nesse tempo eu não usei droga depois eu recaí e aí eu vi que não conseguia parar sozinho não fui internado em clínica nenhuma voltei de novo pra cá tô me sentindo bem desde março pra cá não tive mais problema com droga. (E8U)

A satisfação e a percepção de mudanças, como salientado, foram referidas de maneira associada nas construções compartilhadas pelo grupo de usuários, podendo-se denotar, em virtude de alguns relatos, tratar-se de uma dinâmica de causa e efeito, na qual a satisfação aparece como consequência da percepção de mudanças positivas, conforme pode-se observar nas seguintes falas:

Tô satisfeito porque eu tenho visto mudança na minha vida [...] eu tenho achado bom o serviço [...] os profissionais sabem lidar com nós eles se preocupam em saber como a gente tá lidando então eu acho que o grupo ajuda bastante nesse lado aí de entender o usuário que sou eu [...] as atividades que eu tenho aqui melhora pra mim porque quando eu não tava na atividade aqui que eu tava na rua eu tava usando droga eu tava bebendo então as atividades de alguma forma elas me ajuda a esquecer um pouco o mundo lá fora entendeu eu com isso aí também vai me ajudando a diminuir o uso. (E5U)

Pra mim tem sido bom foi bom tem sido bom tanto é que eu já vou ter alta aqui e deu tudo certo tudo que eu esperava [...] pra mim foi tudo bom deu tudo certo não sei se com os outros usuários se é do mesmo jeito mas só sei que eu só tenho a agradecer mesmo que foi depois de tanto tempo que de um hospital a outro e lutando sozinha pra largar do álcool e nada de conseguir e cada vez me destruindo mais e aqui melhorei digamos assim $80 \%$ porque eu ainda tô em tratamento né. (E10U)

O grupo salientou que se sente satisfeito com o acolhimento do serviço, sobretudo nos momentos tidos como difíceis de suas vidas, como nas situações de crise, nos problemas de relacionamento familiar, de desemprego, de situação de rua, de recaídas e nos momentos de uso constante de substâncias psicoativas, de acordo com os seguintes relatos:

Eu vim pro Caps porque eu não tinha lugar pra comer aí eu vim me falaram que tinha comida eu vim nesse pensativo mas só que hoje eu já não penso mais assim [...] depois que eu vim aqui comecei a conhecer o grupo comecei a ver que tava melhorando já mudou meu pensamento [...] eu vim aqui por uma decisão agora tô aqui por outra [...] eu até costumo comentar no grupo pra você fazer uma coisa você tem que gostar do que você faz e eu vejo aqui que as pessoas pelo menos as que trabalham neste Caps aqui eu vejo que as pessoas gostam do que faz porque eles cuidam entendeu tipo eles se preocupam com o usuário que sou eu então é bem bacana isso aí. (E5U)

Se você vai na casa de um parente vai te criticar vai reclamar aqui eles já acolhe a gente bem se preocupa como que a gente tá de saúde faz exame [...] você estando aqui dentro você tem a liberdade tem as atividades tem alimentação tem a descontração de poder assistir um filme tem acompanhamento do pessoal eles acolhem a gente parece que eles amam a gente até mais que a própria família que já se cansou mas mesmo assim eles não se cansa da gente tão ali tão lutando com a gente tão preocupado se preocupa até com a nossa aparência. (E2U)

Paralelamente à ênfase dada aos cuidados oferecidos pelo CAPSad, os usuários fizeram alusão à atenção recebida de seus próprios familiares e valeram-se dela como referência para considerar satisfatório o cuidado recebido no serviço. Essa aparente comparação feita pelo grupo de usuários entre as atitudes de seus familiares e a conduta dos profissionais do CAPSad 
pode expressar a relevância do vínculo estabelecido com o serviço, representado pelos usuários como da ordem de um convívio familiar.

Pra mim o Caps intercedeu na minha família [...] minha família fica bem contente quando eu venho no Caps entendeu fica bem contente comigo eles brigam comigo quando eu não venho. $(G U)$

Além de poder expressar a importância que o vínculo com o serviço tem para os usuários, a associação feita pelo grupo entre os cuidados de seus familiares e os cuidados oferecidos pelo serviço também pode caracterizar-se como uma maneira dos usuários estimarem sua satisfação, usando a experiência dos cuidados familiares como parâmetro para avaliar o serviço.

O grupo de usuários realçou, ainda, a compreensão e a resiliência dos profissionais do CAPSad nas situações de recaída dos usuários:

Semana retrasada tive uma recaída mas não é culpa do Caps o culpado foi eu que fui atrás da droga então o pessoal aqui do Caps trata a gente muito bem pelo menos eu da minha parte não tenho o que reclamar do pessoal aqui [...] eles procuram tratar a gente pra gente não recair se recair eu retorno aqui que a gente tem apoio tem ajuda eles não abandonam a gente não é como muitos lugar que quando você recai você não é bem recebido. (E8U)

Também foi valorizada a liberdade de escolha dos usuários em relação à assistência prestada pelo serviço, refletindo na sua corresponsabilização pelo tratamento:

ninguém me obrigou a vir aqui eu vim com as minhas próprias pernas porque pra mim não tava dando mais não chega cansei dessa vida pra mim não dá mais não aguento mais usar droga [...] se eu voltar a usar droga eu morro o médico já falou. (E8U)

\subsection{Avaliação da percepção de mudança dos usuários}

Com relação à mudança percebida, o grupo de usuários também expressou de maneira compartilhada a percepção de que o tratamento oferecido pelo CAPSad proporcionou mudanças positivas em suas vidas, de acordo com as seguintes falas:

Melhorou bastante porque eu cheguei aqui muito mal eu vim acompanhado pela minha família eles me acolheram eu já melhorei $80 \%$. (E1U)

Nota 10 eu já cheguei aqui passei por psicólogo passei por clínico fiz exame a orientação deles também isso muda quando a gente sai a gente sai com a cabeça mais fresca lá pra fora você pensa num objetivo diferente tanto que no tempo que eu tô aqui não tô tendo problema com álcool nem com no meu caso também era a cocaína [...] já me senti diferente porque senão numa hora desta se eu não tivesse aqui com certeza eu já taria bêbado e hoje em dia eu já penso diferente qual é o meu foco de ajuntar de fazer uma renda fixa por mês pra pelo menos arrumar uma pensão e sair do albergue. (E2U)

Mudou minha inteligência já desintoxicou bem eu não conseguia dormir eu tinha pesadelo por causa da droga eu tinha pressentimento que alguém ia me matar entendeu hoje eu melhorei bastante. (E3U)

Mudou porque eи escutei a história das pessoas que frequentam então eu falei toma vergonha na cara para com esse baseado aí cara entendeu. (E4U)

Eu sou dependente químico e também sou alcoólatra e eu tipo eu não tinha controle não vou dizer pra você que eu parei mas hoje eu já tenho um controle umas história que aqui com os profissionais eles tipo de alguma forma nos ajuda porque antes eu não tinha controle hoje eu consigo ter um controle tipo assim antes eu botava mil reais no bolso no outro dia chegava sem nenhum centavo na mão e hoje em dia eu já tenho esse controle [...] eu percebi mudança sim porque antes eu só pensava no uso da droga e hoje eu tenho outros pensamentos eu penso em voltar a trabalhar arrumar um emprego que você não sabe eu moro na rua eu dependo de um serviço social aí pra dormir e tipo hoje eu já tenho outros pensamentos construtivos [...] que antes eu não tinha né. (E5U)

É perceptível a mudança de comportamento até porque eu tenho alguma experiência com profissionais desta área da saúde o meu histórico pessoal com relação ao consumo de álcool e eventualmente de outra droga no caso cocaína já 
foi objeto de tratamento em outras instituições e com outros profissionais inclusive de cunho particular então toda vez e principalmente neste momento em que eu me predisponho a iniciar um tratamento. (E7U)

Meu uso era diário dei uma reduzida né porque eu tive aquele estalar de acordar junto com as atividades que eu já passei aqui e o Acompanhamento médico eu consegui acordar pra vida mesmo porque quando a gente tá no uso constante né a gente entra assim num mundo de escuridão falando por min né eu tava num uso diário então eu creio que eu tive resultado né bem significativo [...] percebi uma grande diferença já não estou no uso constante. (E9U)

Minha vida mudou muito antes eu bebia muito eu bebia bastante eu perdia o controle e agora não e nem tem muito tempo que eu tô aqui eles me ajudaram muito. (E10U)

Eu melhorei [...] no meu caso também [...] eu melhorei bastante. (GU)

Como observado nos relatos, o grupo de usuários percebeu a ocorrência de mudanças benéficas em suas vidas com o tratamento realizado no CAPSad. As mudanças apontadas pelos usuários referiram-se, principalmente, ao próprio uso de substâncias psicoativas e em torno da organização de suas vidas de modo geral.

O grupo de usuários relatou que as mudanças positivas também foram percebidas e valorizadas pelos seus familiares e pelas demais pessoas com as quais os usuários convivem, conforme as seguintes falas:

Eu tava mais envolvido em drogas hoje eu já diminui bastante com a ajuda deles com remédio to melhorando aí faço meu tratamento já consegui voltar a trabalhar [...] fazia 13 anos que eu não falava com as minhas filhas foi onde eu conversei com elas [..] eu pedi ajuda pra referência pedi pra ela ligar pra eu conversar com minhas filhas aí minha exmulher aceitou eu poder falar com as minhas filhas. (E6U)

A mudança do comportamento é visível é sentida por mim e visível pelo meu círculo social quer seja a família mais próxima quer seja o círculo familiar parentesco um pouquinho mais distante ambiente de trabalho ambiente acadêmico e ambiente social em geral. (E7U)

Bastante mudança meu comportamento em casa mudou muito antigamente eu chegava em casa ignorando todo mundo eu queria quebrar as coisas dentro de casa então graças à ajuda que eu tive dos profissionais igual eu tava te falando mudou muita coisa na minha vida a minha família tá contente comigo de eu tá vindo aqui de eu ter procurado ajuda sozinho. $(E 8 U)$

Além da percepção da ocorrência de mudanças relativas ao próprio uso de substâncias psicoativas e em torno da organização de suas vidas, o grupo de usuários fez referências a ocorrência de reforço ou de restabelecimento de seus laços familiares, atribuindo a consecução desses resultados ao tratamento e ao trabalho de mediação feito pelo CAPSad.

\section{Discussão}

Os aspectos condensados na temática do cuidado pelo grupo de usuários referiram-se, sobretudo, ao acolhimento disponibilizado pelo serviço, à resiliência da equipe de profissionais, ao trabalho com as famílias dos usuários e às mudanças relativas ao uso de substâncias psicoativas e à organização de suas vidas.

As construções formuladas pelo grupo de usuários indicaram que o serviço trabalhou em favor do desenvolvimento dos usuários, operando no sentido do fator Paidéia, ou seja, o serviço trabalhou com vistas à coprodução de sujeitos autônomos, uma vez que para o método da Roda, a clínica, a saúde pública e a gestão produzem modos de ser (subjetividades) e a produção de valores de uso tem o potencial para constituir pessoas dependentes ou autônomas. No presente estudo, as mudanças relatadas pelo grupo de usuários dirigiram-se à produção de autonomia, de ampliação da capacidade de análise e de intervenção na sua própria realidade (Campos, 2005a, 2005b).

O acolhimento, como tecnologia relacional, deve estar pautado pelos princípios da empatia, atitude orientadora, genuinidade e congruência. Nesse sentido, para realizar o acolhimento de forma humanizada e construir com o usuário seu projeto terapêutico singular é importante ouvir suas demandas, assumir uma atitude capaz de acolher essas demandas e apresentar 
devolutivas mais adequadas visando permitir que o usuário estabeleça relações que garantam sua independência. $\mathrm{O}$ acolhimento deve ser dirigido às particularidades dos usuários, tratando, inclusive, de questões morais (tabus) que, mesmo inconscientes, podem dificultar o diálogo e a formação de vínculo com o usuário (Vangrelino, Gazeta, Camargo, Garcia, \& Toledo, 2018).

Souza e Melo (2015) apontam que o acolhimento não se restringe às etapas de recepção e triagem dos usuários, mas extrapola esses momentos, devendo perpassar todos as oportunidades de interação entre a equipe e os usuários.

A atitude de resiliência da equipe de profissionais foi destacada pelos usuários, que a reconheceram principalmente nos momentos de ocorrência de recaídas. A importância da resiliência dos profissionais foi apontada em estudo desenvolvido em um serviço de saúde mental para jovens adultos usuários de substâncias, o qual demonstrou que os pacientes apreciam profissionais esperançosos e de mente aberta, que transmitam confiança a eles, que não desistam deles e que os ajudem a resolver os problemas e a tomar as melhores decisões para suas vidas (Ness, Kvello, Borg, Semb, \& Davidson, 2017).

Nesse mesmo estudo, os pacientes valorizaram o atendimento baseado em práticas colaborativas, que podem ser definidas como as relações nas quais a equipe de profissionais demonstra respeito pelas perspectivas dos usuários, bem como pelas parcerias e relacionamentos nos quais os usuários estão envolvidos. Essa maneira de colaborar envolve um processo dinâmico e mútuo de compartilhamento de intenções e compromissos, mantendo as interações abertas e flexíveis. $\mathrm{O}$ atendimento como prática colaborativa corresponde a um processo contínuo, orientado por julgamentos e tomada de decisões compartilhadas, transmitindo confiança, flexibilidade, trabalho em equipe, parceria, cooperação em direção a objetivos compartilhados (Ness, Kvello, Borg, Semb, \& Davidson, 2017).

O papel do serviço na preservação, recuperação e fortalecimento dos vínculos familiares dos usuários também emergiu com relevância nas construções compartilhadas pelo grupo, que associou os cuidados oferecidos pelo CAPSad aos cuidados de seus familiares, apontando uma possível maneira de estimarem sua satisfação com o serviço.

$\mathrm{O}$ atendimento à família, constituindo-se como uma das atribuições dos CAPSad, configura-se como um convite aos familiares para participarem do tratamento dos usuários como parceiros do serviço, contribuindo para o fortalecimento e resgate dos vínculos familiares, a exemplo do que se verifica em outros países, nos quais as políticas públicas enfatizam a necessidade de incluir os familiares no planejamento do tratamento em saúde mental, a fim de ajuda-los a lidar com as dificuldades práticas e psicológicas relacionadas a seu papel de cuidadores (Giacco, Fiorillo, Del Vecchio, Kallert, Onchev, et al., 2012).

Além de colaborar com o serviço no papel de cuidadores, a presença dos familiares no serviço é importante no aspecto terapêutico para os próprios familiares, na medida em que o sofrimento psíquico não se restringe ao paciente, mas envolve também sua esfera social, especialmente seu círculo familiar, que necessita se reorganizar em função das demandas dos paciente. No contexto problemático do consumo de substâncias, as famílias são abaladas pelas circunstâncias de crise e estresse, demandando da equipe de profissionais uma atenção direcionada a compreender suas limitações e necessidades, valorizando a maneira pela qual enfrentam as situações e resolvem seus problemas (Zerbetto, Galera \& Ruiz 2017).

É importante oferecer apoio à rede social na qual o usuário de substâncias está inserido, principalmente sua família, com o objetivo de modificar a estrutura vulnerável decorrente do processo de dependência. Portanto, uma das vertentes do atendimento do serviço reside em trabalhar com os usuários a questão do convívio familiar, que porventura foi perdido, na medida em que os vínculos familiares podem ser rompidos ou fragilizados devido às circunstâncias geradas pela dependência química, pois o processo de reabilitação é favorecido quando o usuário é provido por um conjunto de apoios, como a família, grupos e rede de amigos (Souza \& Melo, 2015).

Os relatos dos usuários ilustraram que os processos terapêuticos empregados no serviço foram norteados pelas estratégias de redução de danos, as quais estão dirigidas ao tratamento seguro em face dos comportamentos de risco e dos danos a eles associados. Essas estratégias pressupõem a ideia de que se vive em um mundo real (diverso de um mundo ideal), no qual 
são encontradas maneiras alternativas de reduzir prejuízos maiores, levando-se sempre em conta o respeito à liberdade de escolha dos usuários (Queiroz, 2001; Delza, Oliveira, Soares, Domanico \& Pinho, 2017).

Contudo, atualmente observamos mudanças nas políticas que norteiam a assistência em saúde mental em álcool e drogas. As alterações realizadas recentemente nessas políticas priorizaram a abstinência em relação às estratégias de redução de danos e passaram a desconsiderar os serviços de atenção psicossocial como substitutivos aos serviços de caráter manicomial. Além disso, as mudanças legitimaram as comunidades terapêuticas como estratégicas no tratamento de usuários de substâncias e incluíram os hospitais psiquiátricos e os ambulatórios de saúde mental na Rede de Atenção Psicossocial (Brasil, 2019).

Essas recentes alterações privilegiam a psiquiatria em detrimento dos demais campos do conhecimento, da clínica ampliada e do trabalho em equipe, fortalecendo a lógica de mercado e implicando na desconstrução de direitos conquistados ao longo de décadas no processo da Reforma Psiquiátrica Brasileira (RPB) (Guimarães, \& Rosa, 2019).

\section{Considerações Finais}

As construções compartilhadas pelo grupo de usuários do CAPSad apresentaram os sentidos, os significados e os valores dados à satisfação e à percepção de mudanças decorrentes do tratamento oferecido pelo serviço, contribuindo para complementar e aprofundar o conhecimento consolidado pelas pesquisas de abordagem quantitativa realizadas nos serviços de atenção psicossocial em álcool e outras drogas.

A avaliação da satisfação e da percepção de mudança dos usuários do serviço apresentou certa relação de causa e efeito, na medida em que alguns relatos acerca da satisfação aludiram às mudanças decorrentes do tratamento no CAPSad,

Os resultados do estudo convergiram para aspectos do cuidado em saúde ligados ao acolhimento, à resiliência da equipe, ao trabalho com as famílias e às mudanças quanto ao uso de substâncias e à própria organização de vida dos usuários.

Apesar dos resultados do estudo evidenciarem as potencialidades dos CAPSad no cuidado das pessoas que fazem uso problemático de álcool e outras drogas e justificarem a necessidade de sua ampliação na rede de serviços extra-hospitalares, observamos atualmente a edição de políticas públicas que contrastam com os pressupostos da RPB e que enfraquecem a rede baseada no modelo da atenção psicossocial.

As considerações do presente estudo podem servir como indicadores para realização de futuras pesquisas de avaliação de serviços de atenção psicossocial em álcool e outras drogas.

\section{Referências}

Bandeira, M., Felicio, C. M., \& Cesari, L. (2010). Validação da escala de percepção de mudanças pelos familiares como medida de resultado do tratamento em serviços de saúde mental. Revista Brasileira de Psiquiatria, 32(3), 283-287. http://doi:10.1590/S1516-44462010005000010

Bandeira, M. B., Andrade, M. C. R., Costa, C. S., \& Silva, M. A. (2011). Percepção dos pacientes sobre o tratamento em serviços de saúde mental: validação da escala de mudança percebida. Psicologia: Reflexão e Crítica, 24(2), 236-243. http://www.scielo.br/pdf/prc/v24n2/04.pdf

Barbosa, G. C. (2013). Avaliação do centro de atenção psicossocial em álcool e outras drogas do município de Botucatu. (Tese de Doutoramento, Escola de Enfermagem da Universidade de São Paulo, São Paulo). http://www.teses.usp.br/teses/disponiveis/7/7141/tde-14072014-093437/

Brasil. (2009). Ministério da Saúde. Portaria n. 31.190 de 04 de junho de 2009. Institui o Plano Emergencial de Ampliação do Acesso ao Tratamento e Prevenção em Álcool e outras Drogas no Sistema Único de Saúde - SUS (PEAD 2009-2010) e define suas diretrizes gerais, ações e metas. http://bvsms.saude.gov.br/bvs/saudelegis/gm/2009/prt1190_04_06_2009.html

Brasil. (2012). Ministério da Saúde. Resolução no 466 de 12 de dezembro de 2012. Diretrizes e normas regulamentadoras de pesquisas envolvendo seres humanos. http://bvsms.saude.gov.br/bvs/saudelegis/cns/2013/res0466_12_12_2012.html

Brasil. (2016). Ministério da Saúde. Resolução no 510 de 07 de abril de 2016. http://conselho.saude.gov.br/resolucoes/2016/reso510.pdf

Brasil. (2019) Nota Técnica n. 11, de 2019. Esclarecimentos sobre as mudanças na Política Nacional de Saúde Mental e nas Diretrizes da Política Nacional sobre Drogas.http://pbpd.org.br/wp-content/uploads/2019/02/0656ad6e.pdf

Campos, G. W. S. (2005a). Saúde Paidéia (2a ed). HUCITEC. 
Campos, G. W. S. (2005b). Um método para análise e cogestão de coletivos: a constituição do sujeito, a produção de valor de uso e a democracia em instituições: o método da roda (2 ${ }^{\mathrm{a}}$ ed). São Paulo: HUCITEC.

Furtado, J. P. (2001). Um método construtivista para a avaliação em saúde. Ciência \& Saúde Coletiva, 6(1), 165-181. http://dx.doi.org/10.1590/S141381232001000100014

Giacco, D., Fiorillo, A., Vecchio, V., Kallert, T., Onchev, G., Raboch,J. ... Priebe, S. (2012). Caregivers' appraisals of patients' involuntary hospital treatment: european multicentre study. The British Journal of Psychiatry, 201, 486-91. https://www.cambridge.org/core/services/aop-cambridgecore/content/view/1CFC54A150575DA5CFA263236C23BA79/S0007125000237100a.pdf/caregivers_appraisals_of_patients_involuntary_hospital_treatment_ european_multicentre_study.pdf

Gonçalves, R. M. D. A. (2016). Avaliação dos Centos de Atenção Psicossocial em Álcool e outras Drogas do Estado de Minas Gerais. (Tese de Doutoramento, Escola de Enfermagem da Universidade de São Paulo, São Paulo). http://www.teses.usp.br/teses/disponiveis/7/7141/tde-10052017-143617/pt-br.php Gonçalves, R. M. D. A., Oliveira, M.A.F., Claro, H.G., Pinho, P.H., Prates, J.G., \& Tarifa, R.R. (2016). Processo e resultado do cuidado em álcool e outras drogas. Journal of Nursing UFPE on line, 11(2), 523-533. https://periodicos.ufpe.br/revistas/revistaenfermagem/article/view/11970/14514

Guba, E. G., \& Lincoln, Y. S. (2011). Avaliação de quarta geração. Unicamp.

Guimarães, T. A., \& Rosa, L. C. S. (2019) A remanicomialização do cuidado em saúde mental no Brasil no período de 2010-2019: análise de uma conjuntura antirreformista. OSocial em Questão, 22(44), 111-138. http://osocialemquestao.ser.puc-rio.br/media/OSQ_44_art5.pdf

Minayo, M. C. S. (2017). Amostragem e saturação em pesquisa qualitativa: consensos e controvérsias. Revista Pesquisa Qualitativa, 5(7), 1-12. file:///C:/Users/rhsso/Downloads/82-250-1-PB\%20(1).pdf

Ness, O., Kvello, Ø., Borg, M., Semb, R., \& Davidson, L. (2017). “Sorting things out together”: Young adults' experiences of collaborative practices in mental health and substance use care. American Journal of Psychiatric Rehabilitation, 20(2), 126-142. https://doi.org/10.1080/15487768.2017.1302369

Pinho, P. H., (2014). Avaliação dos centros de atenção psicossocial em álcool e outras drogas do município de São Paulo. (Tese de Doutoramento, Escola de Enfermagem da Universidade de São Paulo, São Paulo). http://www.teses.usp.br/teses/disponiveis/7/7141/tde-17112014-144843/

Queiroz, I. S. (2001). Os programas de redução de danos como espaços de exercício da cidadania dos usuários de drogas. Psicologia: Ciência e Profissão, 21(4), 2-15. http://dx.doi:10.1590/S1414-98932001000400002

Souza, D. R., Oliveira, M. A. F., Soares, R. H., Domanico, A., \& Pinho, P. H. (2017). Resistências dos profissionais da atenção psicossocial em álcool/drogas à abordagem de redução de danos. Journal of Nursing and Health, 7(1), 16-24. https://periodicos.ufpel.edu.br/ojs2/index.php/enfermagem/article/view/9276

Souza, S. D. L., \& Melo, L. G. (2015). Acolhimento aos usuários de crack de um Centro de Atenção Psicossocial: os sentidos atribuídos pelos trabalhadores. SMAD. Revista Eletrônica Saúde Mental Álcool e Drogas (Edição Em Português), 11(4), 181. https://doi.org/10.11606/issn.1806-6976.v11i4p181-189

Vangrelino, A. C. dos S., Gazeta, A. do A., Camargo, I. de, Garcia, A. P. R. F., \& Toledo, V. P. (2018). Psychoactive substance user embracement by the multiprofessional team of the Psychosocial Care Center III. SMAD. Revista Eletrônica Saúde Mental Álcool e Drogas, 14(2), 65-72. https://doi.org/10.11606/issn.1806-6976.smad.2018.000321

Wetzel, C. (2005). Avaliação de serviço em saúde mental: a construção de um processo participativo. (Tese de Doutoramento, Escola de Enfermagem de Ribeirão Preto da Universidade de São Paulo, Ribeirão Preto). file:///C:/Users/rhsso/Downloads/ChristineWetzel\%20(3).pdf

Zerbetto, S. R., Galera, S. A. F., \& Ruiz, B. O. (2017). Family resilience and chemical dependency: perception of mental health professionals. Revista Brasileira de Enfermagem, 70(6), 1184-1190. https://doi.org/10.1590/0034-7167-2016-0476 